\title{
Evaluation of Fe uptake and transport mechanism of rice plants in a paddy field using $\mathrm{Fe}$ isotope fractionation
}

\author{
GuOJUn Chen ${ }^{1,2, *}$, TONGXU LiU ${ }^{1,2}$, YONGZHU Li ${ }^{1,2}$, \\ TING GAO ${ }^{1,2}$, FANGBAI LI $^{1,2}$ \\ ${ }^{1}$ Guangdong Key Laboratory of Agricultural Environment \\ Pollution Integrated Control, Guangdong Institute of Eco- \\ Environmental Science \& Technology, Guangzhou \\ 510650, P. R. China \\ ${ }^{2}$ State Key Laboratory of Environmental Geochemistry, \\ Institute of Geochemistry, Chinese Academy of Sciences, \\ Guiyang 550081, China \\ * Correspondence: gjchen@soil.gd.cn
}

Two distinct mechanisms for Fe uptake and transport by plants have been developed, which are known as strategy I (Fe(III) reduction) and strategy II (Fe(III)-ligand complex chelation). The mechanism of $\mathrm{Fe}$ uptake and transport in rice plants is still not well understood. Fe isotope fractionation analysis is a promising approach for the assessment of $\mathrm{Fe}$ uptake and transport in the soil-rice system of the paddy field. Here, $\mathrm{Fe}$ isotopic compositions of different tissues (including roots, stems, leaves, panicles, husks, and seeds) of rice plants during jointing and maturity stages in the soil-rice system were determined. The rice plants were enriched in heavier $\mathrm{Fe}$ isotopes by about $0.6 \%$ compared to soil. Five leaves or four stems at different heights exhibit limited $\mathrm{Fe}$ isotope variations. While $\mathrm{Fe}$ accumulation in the mature stage was higher than that in the jointing stage, $\mathrm{Fe}$ isotopic compositions of different tissues of rice plants were identical within error. These findings indicated that the mechanism for Fe uptake and transport for rice plants in the paddy field was $\mathrm{Fe}(\mathrm{III})$-ligand complex chelation in the absence of $\mathrm{Fe}$ (III) reduction. The $\mathrm{Fe}(\mathrm{III})$-ligand complex was converted from $\mathrm{Fe}(\mathrm{III})$-phytosiderophore (PS) into $\mathrm{Fe}(\mathrm{III})$-citrate during $\mathrm{Fe}$ transport from roots to stems. Fe isotope fractionation between roots and stems $\left(\Delta^{56} \mathrm{Fe}_{\text {root-stem }}\right)$ was $-1.6 \%$, which was consistent with that between $\mathrm{Fe}(\mathrm{III})$-citrate and $\mathrm{Fe}(\mathrm{III})$ PS from previous $A b$ initio calculations. In addition, the $\mathrm{Fe}$ isotopic compositions of soil, porewater, and $\mathrm{Fe}$ plaque of rhizosphere were measured. The $\mathrm{HCl}$ extraction for soil did not lead to $\mathrm{Fe}$ isotope fractionation, indicating protonpromoted dissolution of $\mathrm{Fe}$ (oxyhydr)oxides in soil. This study confirms that the $\mathrm{Fe}$ isotope fractionation analysis is a powerful tool for investigating the mechanism of Fe uptake and transport for rice plants, and would be helpful for understanding plant physiological processes. 